\title{
Genetic Divergence Analysis in Aromatic and Non- Aromatic Germplasm of Rice
}

\author{
Parte Deepika*, Singh Sanjay and Tiwari Shweta \\ Department of Plant Breeding and Genetics, College of Agriculture, Jawaharlal Nehru Krishi \\ Vishwa Vidyalaya, Jabalpur - 482004, Madhya Pradesh, India \\ *Corresponding author
}

\begin{tabular}{l} 
Ke y w o r d s \\
Genetic divergence, \\
Cluster analysis, D \\
statistics, \\
Germplasm \\
\hline Article Info \\
\hline $\begin{array}{l}\text { Accepted: } \\
\text { 05 June } 2020 \\
\text { Available Online: } \\
\text { 10 July } 2020\end{array}$ \\
\hline
\end{tabular}

\section{Keywords}

Genetic divergence, Cluster analysis, $\mathrm{D}^{2}$ statistics,

Germplasm

Accepted:

05 June 2020

10 July 2020

\section{A B S T R A C T}

The genetic diversity estimation was carried out in sixty seven germplasm of rice using Mahalanobis D2 by considering 32 yield and quality characters. ANOVA revealed the presence of considerable amount of variability among the genotypes studied. Thousand (1000) grain weight contributed $47.76 \%$ of total genetic divergence followed by grain length (15.88\%) and Number of spikelet per panicle $(8.01 \%)$.It also manifested that genotypes were grouped into twelve clusters. Cluster I, III, V and VIII containing maximum genotypes with highest intra-cluster distances. While, clusters IX and X (D2=13160.30) followed by VIII and IX (D2=9440.02) as well as VII and X (D2 =5965.22) were highly diverse from each other as these clusters showed maximum intercluster distance. Hence, genotypes belonging to these clusters could be chosen as parents in hybridization programme Genotypes Madhuri, DhaniyaDhan, NPT 14-6, LalJeera, Kalimuch, Mohan Bhog, Tarori Basmati and Padma reported as most divergence and chances of finding the desirable recombinants after hybridization could be more.

\section{Introduction}

Rice belongs to the genus Oryza family Poaceae and subfamily bambusoideae, has two cultivated and 22 wild species. Nine of the wild species are tetraploid $(2 n=48)$. The remaining wild species and the two cultivated species are diploid $(2 \mathrm{n}=24)$. The cultivated species are Oryza sativa and Oryza glaberrima. Asian cultivated rice, Oryza sativa, is grown widely while the growth of Oryza glaberrima, the African cultivated rice, is limited to West Africa. Asian cultivated rice varieties were domesticated from the common wild rice ancestor Oryza rufipogon, under both natural and human selection pressures, and displays large genetic diversity across a thousand varieties. 
Rice is the most important food crop for people in low and middle-income countries and staple food of more than half of the world's population. It is a source of complex carbohydrates. Globally nine out of ten people eat rice belong to Asian regions and are generally poor and consume only $50-80 \%$ of daily calorie intake. The crop contributes 19 $\%$ of the world's human per capita energy and $13 \%$ of per capita protein. As expected, Asia accounts for over $80 \%$ of the world's production of rice, with China, India, and Indonesia producing the most. Only 6-7\% of the world's rice crop is traded in the world market.

India is the second-largest producer and consumer of rice, 100 million tons rice consumed in 2018-19 It occupies $11 \%$ of the world's total cultivated area which is estimated to have 161.54 million hectares during 2017-18 with production and productivity of 487.46 million metric tons and 4.5 metric tons per hectare during 2017-18. In India area, production and productivity of rice is 43.86 million ha, 104.32 million tons, and $2404 \mathrm{~kg} / \mathrm{ha}$ (Mythili et al., 2018). During Kharif, Madhya Pradesh covered the maximum area under rice cultivation. The total cultivated area under rice was 2024 ha., productivity 5320 million tonnes, and yield $2628 \mathrm{~kg} / \mathrm{ha}$ in 2015-16.

(http://slbcmadhyapradesh.in/agriculture.aspx - Bing).

Traditional varieties contain huge diversity in grain shape, size, colour, and nutritive value, some varieties which have aroma also contain iron and zinc. Black color rice contains antioxidant properties which are good for human health. Scientific studies suggested that these color pigments have antioxidant properties that may be useful to human health. Diverse plant types are immediately valuable for shaping new varieties. The existence of genetic diversity is a desirable requirement for any crop breeding program. $\mathrm{D}^{2}$ analysis is an important technique for quantifying genetic divergence hence, it helps in the identification of genetically divergent parents for their use in breeding programs. The success of Breeding Programmes can be enhanced when variability within the existing genotypes is high, which may allow the selection of elite ones for the development of new varieties.

The present investigation a total of 67 rice genotypes were collected from different ricegrowing areas of Madhya Pradesh and these lines were undertaken to ascertain the genetic divergence among the genotypes and to find out the relationship between geographical and genetic diversity among the set of characters studied related to fitness and productivity. There is good scope to bring about genetic improvement in rice through hybridization and selection by crossing accessions from different clusters (Praveen et al., 2016).

\section{Materials and Methods}

The a field experiment was carried out during Kharif season 2018-2019, at Seed Breeding Farm, Department of and Plant Breeding and Genetics, College Of Agriculture, JNKVV, Jabalpur (M.P.). The experimental area occupied was quite uniform concerning topography and fertility. This area as per the National Bureau of Soil Science and Land Use Planning of ICAR comes under agroecological sub-region number 10.1 as subhumid dry ecoregion. The soil of experimental areas was clayey loam with uniform topography. It is situated at $23.90 \mathrm{~N}$ latitude and $79.58 \mathrm{E}$ longitudes at an altitude of $411.87 \mathrm{~m}$ above the mean sea level.

The experimental material consists of 67 (aromatic and non-aromatic) rice genotypes collected from different rice-growing areas of Madhya Pradesh to assess the genetic 
diversity. The genotypes were sown in a Randomized Block Design (RBD) with fourrow of each genotype and spacing $15 \mathrm{~cm}$ between plant and $20 \mathrm{~cm}$ between rows. The standard agronomic practices were adopted for normal crop growth. The observations were recorded on five randomly taken plants from each plot for twenty three quantitative traits viz., Days to panicle initiation (days), Days to $50 \%$ flowering (days), Flag leaf length $(\mathrm{cm})$, Flag leaf width $(\mathrm{cm})$, Culm length $(\mathrm{cm})$, Culm thickness $(\mathrm{mm})$, Plant height $(\mathrm{cm})$, Number of tillers/plant, Number of productive tillers/plant, Panicle length $(\mathrm{cm})$, Average panicle weight per plant $(\mathrm{g})$, Days to maturity (days), Number of spikelets per panicle, Fertile spikelets per panicle, Sterile spikelets per panicle, Spikelet fertility $(\%)$, Spikelet density (\%), Biological yield/plant (g), Plant weight (g), Panicle index (\%), Harvest index (\%), Thousand grain weight (g) and Grain yield/plant (g). And fourteen quality characters viz., Grain length (mm), Grain breadth ( $\mathrm{mm})$, Length and breadth ratio $(\mathrm{L} / \mathrm{B})$, Decorticated grain length $(\mathrm{mm})$, Decorticated grain breadth $(\mathrm{mm})$, Length to breadth ratio of decorticated grain, Hulling (\%), Milling (\%), Head rice recovery $(\%)$, decorticated grain: Shape (in lateral view), cooked rice length, cooked rice breadth, Cooked grain length breadth ratio, length elongation ratio (LER) and breadth elongation ratio (BER). The data were analyzed as per the multivariate analysis of genetic divergence using $\mathrm{D}^{2}$ statistics ${ }^{4}$. The genotypes were grouped into different clusters further described by following Tocher's method (Rao et al., 1952).

\section{Results and Discussion}

The analysis of variance revealed significant differences among the genotypes for all the characters. The quantitative assessment of genetic divergence has been studied using Mahalanobis $\mathrm{D}^{2}$ statistics on 67 genotypes over 32 yield and quality attributing traits. Genetic diversity depicted by cluster diagram and clusters may provide a resemblance of the genetic architecture of the plant population studied. The earlier workers studied genetic divergence and concluded that all the traits studied contributed differently towards genetic divergence and no relationship was observed between geographical origin and genetic diversity (Singh et al., 1999), (Bharadwaj et al., 2001), (Sood., 2005).

The character thousand-grain weight (g) contributed maximum genetic divergence $(47.76 \%)$ followed by grain length $(15.88 \%)$ and number of spikelets per panicle $(8.01 \%)$, as represented in Table No.1. The result aligned with previous workers (Chauhan et al., 1994), (Shahidullah et al., 2009), (Nayak et al., 2004), (Kole., 2000) The study revealed that the landraces contain optimum variability for economic traits and thus the material can be utilized further for allelic characterization of locus exhibiting thousand-grain weight traits. Some traits viz. days to maturity, flag leaf length, flag leaf width, stem thickness, plant height, number of tillers, number of productive tillers, length of a panicle of the main axis, spikelets density, harvest index, and hulling $\%$ had no contribution towards divergence. This result supported by workers (Chauhan et al., 1994), (Babu et al., 2006), (Jha et al., 2014), (Kumar et al., 2015). In this study, plant height had no contribution to genetic divergence. This was not in support with the findings of researchers who found the variability for the height traits (Jha et al., 2014), (Kumar et al., 2008).

On the basis of divergence values, 67 genotypes were grouped into 12 clusters using Tocher's method. The cluster I was polygenotypic (38 genotypes) followed by III (12 genotypes), V (7 genotypes) and VIII (2 genotypes) while 8 clusters II, IV, VI, VII, IX, X, XI, and XII were mono-genotypic 
(having 1 genotype each), which is displayed in Table No.2. This group constellation articulated the presence of genetic variability. The eight clusters with a single genotype elucidate the unique characterization which can be introgressed in the future to release promising genotypes. The genetic diversity present in other clusters belonging to same geographical location may be due to selection pressure, selection criteria and environmental conditions (Vivekanandan and Subramanian, 1993 and Nayak et al., 2004).

The average intra and inter-cluster values estimated as per the procedure given by Singh and Choudhary (1977). Cluster V showed maximum intracluster value $\left(\mathrm{D}^{2}=1188.28\right)$ followed by Cluster III $\left(\mathrm{D}^{2}=993.67\right)$, Cluster I $\left(\mathrm{D}^{2}=863.95\right)$ and Cluster VIII $\left(\mathrm{D}^{2}=539.35\right)$, hence, they can be selected as hybridization stock for the next-generation breeding program. Cluster II, IV, VI, VII, IX, X, XI, and XII were solitary clusters with no intracluster distance. The result is represented in Table No.3. The inter-cluster value was maximum between clusters IX and $\mathrm{X}\left(\mathrm{D}^{2}=\right.$ 13160.30) while it was minimum between clusters IV and VII $\left(\mathrm{D}^{2}=468.07\right)$ as shown in Table No.4. The genotypes of cluster IX (Vishnu Bhog) showing the higher intercluster distance with cluster X (PS 4) followed by cluster VII (Kalimuch) with X (PS-4), cluster VIII (Mohan Bhog, Tarori Basmati) with IX (Vishnu Bhog), cluster X (PS-4) with XII (DhaniyaDhan), cluster I (NPT 14-2, NPT 14-3, Jeera Shankar, Tulsi Das, AsamChuni, NPT 14-4, JGL 3844, Azuba, JagtiyalSanalu, WGL 23985, NPT 145, JGL 3828, WGL 32100, Sitachandan, HMT, BPT-5204, WGL-14, BadshahBhog, Ram Bhog, Chinnor, YSR JR-7, NPT14-1, WGL 32183, Kalanamak, Chintu, Daftari, Sonam, SafedAasma, Dubraj, MTU1081, JamunSurkhi, BhataPhool, Krishna Bhog, Balaghat Luchai, Chinoor, Assam Koti, Shriram, Brijbhog) with X (PS 4). These high inter cluster distance signifies the most divergent gene pool, which may be utilized as parents in the hybridization breeding program. It is well known that crosses between divergent parents usually produce a greater heterotic effect than between closely related ones (Ranjith et al., 2018)' Therefore, cross between prominent genotypes falling in distant clusters exploits maximum heterosis and may lead to the development of potential genotypes with broaden genetic base.

The cluster mean values for each of the 32 characters are presented in Table No.5 depicting a wide range of variation for all the traits studied. The high cluster mean value interpreted for most of the quality characters by individual cluster II (Madhuri) for Hulling $\%$, milling \%, breadth elongation ratio, Cluster V (PS 1460, Pusa Basmati 1, NPT 1410, Karnal Basmati, PS 5 and MR 219) for grain length. Cluster X (PS 4) for decorticated grain length, decorticated length breadth ratio, cooked grain length, length elongation ratio, and cluster XII (DhaniyaDhan) for grain breadth, decorticated grain breadth, and cooked grain breadth. Thus, germplasms of these clusters indulge potential variability for quality attributes and their cross can generate an ideotype with maximum quality traits together.

The phonological and yield attributing traits illustrated to be highest for genotypes belonging to clusters IV (NPT 14-6), VI (LalJeera), VII (Kalimuch), VIII (Mohan Bhog and Tarori Basmati) and XI (Padma). Therefore, these traits regarded as a beneficial source of gene for improvement of phonological, yield, and quality parameters. Therefore, intercrossing of genotypes involved in these clusters would be useful for inducing variability in respective characters and their rational improvement for increasing the grain yield (Vora et al., 2016) 
Table.1 Contribution of different characters towards divergence in 67 rice genotypes

\begin{tabular}{|c|c|c|c|}
\hline S.No. & Character & $\begin{array}{c}\text { Times ranked } \\
\text { 1st }\end{array}$ & Percentage of contribution towards divergence \\
\hline 1 & Thousand grain weight(g) & 1056 & $47.76 \%$ \\
\hline 2 & Grain length $(\mathrm{cm})$ & 351 & $15.88 \%$ \\
\hline 3 & Number of spikelet per panicle & 177 & $8.01 \%$ \\
\hline 4 & Head rice recovery & 165 & $7.46 \%$ \\
\hline 5 & Stem length $(\mathrm{cm})$ & 126 & $5.70 \%$ \\
\hline 6 & Fertile spikelet per panicle & 072 & $3.26 \%$ \\
\hline 7 & Cooked grain breadth $(\mathrm{cm})$ & 048 & $2.17 \%$ \\
\hline 8 & Biological yield per plant & 038 & $1.72 \%$ \\
\hline 9 & Panicle index & 030 & $1.36 \%$ \\
\hline 10 & Milling \% & 030 & $1.36 \%$ \\
\hline 11 & Breadth elongation ratio & 028 & $1.27 \%$ \\
\hline 12 & Cooked grain length $(\mathrm{cm})$ & 023 & $1.04 \%$ \\
\hline 13 & Grain breadth $(\mathrm{cm})$ & 015 & $0.68 \%$ \\
\hline 14 & Length elongation ratio & 013 & $0.59 \%$ \\
\hline 15 & Grain yield per plant $(\mathrm{g})$ & 011 & $0.50 \%$ \\
\hline 16 & Decorticated grain length $(\mathrm{cm})$ & 008 & $0.36 \%$ \\
\hline 17 & Decorticated grain breadth $(\mathrm{cm})$ & 007 & $0.32 \%$ \\
\hline 18 & Days to $50 \%$ flowering & 005 & $0.23 \%$ \\
\hline 19 & Spikelet fertility\% & 004 & $0.18 \%$ \\
\hline 20 & $\mathrm{~L} / \mathrm{b}$ ratio of decorticated grain & 003 & $0.14 \%$ \\
\hline 21 & Panicle weight per plant (g) & 001 & $0.05 \%$ \\
\hline
\end{tabular}


Table.2 Distribution of rice genotypes in different clusters

\begin{tabular}{|c|c|c|}
\hline Cluster & $\begin{array}{l}\text { Number of } \\
\text { genotypes }\end{array}$ & Genotypes \\
\hline 1 & 38 & $\begin{array}{l}\text { NPT 14-2, NPT 14-3,Jeera Shankar, Tulsi Das, AsamChuni, NPT 14-4, JGL 3844, Azuba, JagtiyalSanalu, } \\
\text { WGL 23985,NPT 14-5,JGL 3828, WGL 32100, Sitachandan, HMT, BPT-5204, WGL-14, BadshahBhog, } \\
\text { Ram Bhog, Chinnor, JR-7, NPT14-1, WGL 32183, Kalanamak, Chintu, Daftari, Sonam, SafedAasma, } \\
\text { Dubraj, MTU1081, JamunSurkhi, BhataPhool, Krishna Bhog, Balaghat Luchai, Chinoor, Assam Koti, } \\
\text { Shriram, Brijbhog. }\end{array}$ \\
\hline 2 & 1 & Madhuri \\
\hline 3 & 12 & $\begin{array}{l}\text { Sukarphool, Chhatriya, Chhindphool, ChotiLuchai, Chhatri, JeeraPhool, Basmatiya, ChhindiKapoor, Karan } \\
\text { Phool, TulsiAmrit, KadamBhog, NPT 14-7. }\end{array}$ \\
\hline 4 & 1 & NPT14-6 \\
\hline 5 & 7 & PS 1460, Pusa Basmati 1, NPT 14-10, Karnal Basmati, PS 5, MR 219, PS 3 \\
\hline 6 & 1 & LalJeera \\
\hline 7 & 1 & Kalimuch \\
\hline 8 & 2 & Mohan Bhog, Tarori Basmati \\
\hline 9 & 1 & Vishnu Bhog \\
\hline 10 & 1 & PS 4 \\
\hline 11 & 1 & Padma \\
\hline 12 & 1 & DhaniyaDhan \\
\hline
\end{tabular}

Table.3 Intra cluster $\mathrm{D}^{2}$ value

\begin{tabular}{|l|l|}
\hline Intra Clusters Distance & $\mathbf{D}^{\mathbf{2}}$ value \\
\hline V & 1188.28 \\
\hline III & 993.67 \\
\hline I & 863.95 \\
\hline VIII & $\mathbf{5 3 9 . 3 5}$ \\
\hline
\end{tabular}


Table.4 Average intra and inter cluster $\mathrm{D}^{2}$ values of rice genotypes

\begin{tabular}{|c|c|c|c|c|c|c|c|c|c|c|c|c|}
\hline $\begin{array}{c}\text { Cluster } \\
\text { No. }\end{array}$ & I & II & III & IV & $\mathbf{V}$ & VI & VII & VIII & IX & $\mathbf{X}$ & XI & XII \\
\hline I & 863.95 & 1256.27 & 1828.29 & 1251.64 & 3705.15 & 1184.77 & 1365.88 & 5673.68 & 1472.06 & 8598.11 & 2264.73 & 3080.78 \\
\hline II & & $\mathbf{0}$ & 1094.11 & 1002.79 & 1301.41 & 2676.89 & 791.18 & 2823.9 & 3043.07 & 4412.9 & 1665.79 & 3257.83 \\
\hline III & & & 993.67 & 1621.51 & 2447.24 & 2438.11 & 1654.56 & 2641.79 & 3451.04 & 5173.21 & 1736.81 & 2184.95 \\
\hline IV & & & & 0 & 2503.74 & 2518.8 & 468.07 & 3726.27 & 3116.5 & 6563.67 & 1718.81 & 3778.35 \\
\hline V & & & & & 1188.28 & 5996.47 & 1989.78 & 2184.01 & 6587.88 & 2441.81 & 2747.33 & 5708.12 \\
\hline VI & & & & & & 0 & 2813.6 & 7629.68 & 644.48 & 11869.19 & 3016.51 & 2149.17 \\
\hline VII & & & & & & & 0 & 3585.41 & 3380.5 & 5965.22 & 1562.04 & 4221.15 \\
\hline VIII & & & & & & & & 539.35 & 9440.02 & 2355.06 & 3196.08 & 5259.87 \\
\hline IX & & & & & & & & & 0 & 13160.3 & 4100.32 & 3876.71 \\
\hline $\mathbf{X}$ & & & & & & & & & & $\mathbf{0}$ & 6008.41 & 9340.84 \\
\hline XI & & & & & & & & & & & 0 & 3804.54 \\
\hline XII & & & & & & & & & & & & 0 \\
\hline
\end{tabular}


Table.5 Cluster means value of different characters

\begin{tabular}{|c|c|c|c|c|c|c|c|c|c|c|c|c|}
\hline Characters & Cluster I & $\begin{array}{c}\text { Cluster } \\
\text { II }\end{array}$ & Cluster III & $\begin{array}{c}\text { Cluster } \\
\text { IV }\end{array}$ & Cluster V & $\begin{array}{c}\text { Cluster } \\
\text { VI }\end{array}$ & Cluster VII & $\begin{array}{c}\text { Cluster } \\
\text { VIII }\end{array}$ & $\begin{array}{c}\text { Cluster } \\
\text { IX }\end{array}$ & $\begin{array}{c}\text { Cluster } \\
\text { X }\end{array}$ & $\begin{array}{c}\text { Cluster } \\
\text { XI }\end{array}$ & $\begin{array}{c}\text { Cluster } \\
\text { XII }\end{array}$ \\
\hline DFF & 106.31 & 101.00 & 99.72 & 112.33 & 102.67 & 92.33 & 103.33 & 99.00 & 101.67 & 99.00 & 122.00 & 93.00 \\
\hline DTM & 144.86 & 141.00 & 144.53 & 147.33 & 145.00 & 145.33 & 144.00 & 141.67 & 153.33 & 141.00 & 160.00 & 149.00 \\
\hline FLL & 44.43 & 43.27 & 45.51 & 53.40 & 41.73 & 55.97 & 43.17 & 41.90 & 48.63 & 42.17 & 56.54 & 47.00 \\
\hline FLW & 0.93 & 0.87 & 0.88 & 1.10 & 0.85 & 1.07 & 0.80 & 0.82 & 0.90 & 0.73 & 1.23 & 1.10 \\
\hline ST & 7.05 & 8.96 & 7.33 & 11.96 & 7.34 & 7.44 & 7.22 & 7.55 & 6.77 & 6.33 & 7.00 & 6.77 \\
\hline SL & 74.67 & 53.55 & 94.43 & 71.33 & 68.58 & 113.33 & 90.04 & 91.33 & 91.44 & 68.11 & 108.44 & 82.22 \\
\hline PH & 97.79 & 75.33 & 118.86 & 93.78 & 95.32 & 135.47 & 122.26 & 117.77 & 118.77 & 94.10 & 134.33 & 103.44 \\
\hline NOT & 9.98 & 9.44 & 8.97 & 7.56 & 8.85 & 8.00 & 10.44 & 9.95 & 8.78 & 14.11 & 9.89 & 7.67 \\
\hline NOPT & 9.52 & 7.67 & 8.83 & 7.56 & 8.76 & 7.67 & 10.33 & 9.78 & 8.67 & 14.00 & 9.56 & 7.45 \\
\hline PL & 23.12 & 21.78 & 24.42 & 22.44 & 26.74 & 22.14 & 32.22 & 26.44 & 27.33 & 26.00 & 25.88 & 21.22 \\
\hline BYPP & 67.17 & 52.22 & 61.70 & 97.22 & 62.84 & 63.85 & 83.48 & 72.13 & 52.22 & 68.22 & 78.33 & 41.96 \\
\hline PWPP & 32.37 & 36.22 & 30.80 & 46.78 & 35.19 & 16.66 & 51.22 & 37.77 & 25.63 & 36.34 & 46.00 & 19.89 \\
\hline NSPP & 290.20 & 191.00 & 184.50 & 448.67 & 200.76 & 280.33 & 327.33 & 169.67 & 242.00 & 129.00 & 426.67 & 172.00 \\
\hline FSPP & 243.54 & 157.67 & 161.78 & 394.33 & 153.38 & 210.00 & 303.67 & 132.83 & 167.67 & 118.67 & 216.00 & 166.67 \\
\hline SF & 84.00 & 82.55 & 89.38 & 87.89 & 76.67 & 74.88 & 92.77 & 78.11 & 69.30 & 91.99 & 50.66 & 96.89 \\
\hline SD & 12.73 & 8.77 & 7.62 & 20.00 & 7.59 & 12.66 & 10.17 & 6.43 & 8.86 & 4.96 & 16.54 & 8.12 \\
\hline TGW & 14.49 & 18.72 & 20.80 & 18.18 & 23.03 & 12.53 & 18.14 & 30.45 & 9.34 & 30.18 & 21.11 & 20.16 \\
\hline PI & 78.23 & 69.87 & 79.12 & 78.35 & 78.39 & 83.14 & 93.49 & 80.53 & 50.70 & 93.29 & 78.24 & 86.97 \\
\hline HI & 38.65 & 48.53 & 39.87 & 37.71 & 43.70 & 21.70 & 57.38 & 42.07 & 24.87 & 49.66 & 45.99 & 41.30 \\
\hline GL & 7.04 & 8.55 & 7.71 & 8.01 & 10.20 & 5.47 & 8.35 & 9.36 & 5.80 & 11.60 & 8.16 & 5.73 \\
\hline GB & 2.28 & 2.32 & 2.59 & 2.50 & 2.35 & 2.51 & 2.11 & 2.65 & 2.75 & 2.51 & 2.55 & 3.31 \\
\hline DGL & 5.16 & 6.54 & 5.79 & 6.09 & 7.47 & 3.96 & 6.36 & 6.89 & 4.33 & 8.66 & 6.12 & 4.25 \\
\hline DGB & 1.95 & 1.84 & 2.22 & 2.07 & 1.95 & 2.24 & 1.82 & 2.29 & 1.97 & 2.15 & 2.29 & 2.91 \\
\hline DLBR & 2.70 & 3.55 & 2.63 & 2.94 & 3.87 & 1.77 & 3.49 & 3.05 & 2.20 & 4.02 & 2.68 & 1.46 \\
\hline H\% & 81.39 & 84.50 & 80.37 & 81.68 & 79.24 & 76.48 & 80.70 & 78.38 & 84.20 & 78.88 & 79.75 & 77.73 \\
\hline М\% & 75.66 & 80.91 & 73.82 & 77.66 & 75.47 & 71.77 & 76.72 & 75.53 & 76.75 & 72.35 & 76.64 & 71.39 \\
\hline HRR & 62.78 & 67.11 & 42.21 & 50.02 & 56.17 & 61.54 & 68.14 & 39.78 & 58.45 & 40.86 & 67.74 & 24.64 \\
\hline CGL & 6.68 & 8.25 & 7.16 & 7.20 & 10.12 & 5.21 & 6.95 & 7.57 & 6.37 & 13.89 & 6.95 & 5.38 \\
\hline CGB & 2.64 & 2.74 & 2.71 & 2.70 & 2.66 & 2.81 & 2.37 & 2.74 & 2.76 & 2.72 & 2.64 & 3.40 \\
\hline LER & 1.30 & 1.26 & 1.24 & 1.18 & 1.35 & 1.32 & 1.09 & 1.10 & 1.47 & 1.61 & 1.14 & 1.27 \\
\hline BER & 1.37 & 1.49 & 1.22 & 1.30 & 1.38 & 1.26 & 1.30 & 1.21 & 1.40 & 1.26 & 1.15 & 1.17 \\
\hline GYPP & 25.27 & 25.31 & 24.15 & 36.66 & 27.40 & 13.85 & 47.89 & 30.82 & 13.00 & 33.89 & 36.00 & 17.29 \\
\hline
\end{tabular}


In conclusion, the available diversity in the germplasms serves as an insurance against unknown future needs. The more diversity is conserved and made available for future use the better the chance of fulfilling the future demand (Praveen et al., 2016). Through results, it has been concluded that all 67 landraces contribute to genetic diversity with a total of 12 clusters. Amongst them, clusters I, III, V, and VIII with maximum genotypes and high value of intra-cluster distances could be adopted as donor parents in a crop improvement program to procure superior segregates in the future. The choice of parent belonging to clusters with maximum intercluster distance would help in the broadening of a genetic basis through the exploitation of hidden hybrid vigour. As, characters such as thousand-grain weight and grain length committed the highest share in genetic diversity, so helpful in a selection based on these traits. The cluster means analysis revealed that the selection of genotypes having a superior performance for a particular trait could be used in the hybridization program for improvement of that particular character. This finding may be useful for the future breeding program to the improvement of rice genotypes for good yield and quality. Hence, good genetic diversity which is present in this contrast breeding material may disclose the chances of genetic improvement in the research program.

\section{Acknowledgment}

The authors are thankful to the College of Agriculture, Jawaharlal Nehru Krishi Vishwa Vidyalaya, Jabalpur, Madhya Pradesh, India for its support.

\section{References}

1. Anonymous. 2016. http://slbcmadhyapradesh.in/agriculture.a spx - Bing
2. Babu, Ravindra, V., Sandhya Kishore, Shobha Rani N. and Ravichandran., 2006. Genetic divergence analysis using quality traits in rice genotypes (Oryza sativa L.). Oryza., 43(4): 260-263.

3. Bharadwaj, C, Satyavathi, T. and Subramanyam, D., 2001. Evaluation of different classificatory analysis methods in some rice (Oryza sativa L.) collections. Indian Journal of Agricultural Sciences., 71(2): 123-125.

4. Chauhan J.S., and Chauhan V.S., 1994. Genetic analysis of grain dimensions and weight and their association with grain yield in rainfed rice (Oryza sativa L.). Indian Journal of Agriculture Science., 64(9):613-8.

5. Jha, V.B., Sharma, A.K., and Singh, B., 2014. Genetic variability for different quantitative traits in early rice. Annals of Agriculture Biological Research., 19(1):25-28.

6. Kole, P.C., 2000. Genetic divergence in aromatic rice involving induced mutant. Oryza.,37(2): 40-42.

7. Kumar Dushyantha, B.M., 2008. Genetic divergence in red rice. Karnataka Journal of Agricultural Sciences., 21(3): 346-348.

8. Kumar, N., Tiwari, B., Lal, G.M., Mishra, S.P., Katiyar, A. and Khuntey, Y., 2015. Evaluation of rice hybrids (Oryza sativa L.) for yield and its component characters. Indian Research Journal Genetics \&Biotechnology.,7(1): 41-43.

9. Mahalanobis P.C., 1936. On the generalized distance in statistics. Proc. Nat.Inst. Sci., 2: 49-55 (1936).

10. Nayak, A. K., Chaudhary, D. and Reddy, J. N., 2004. Genetic variability and correlation study among quality characters in scented rice. Agric. Sci. Digest., 23(3): 175-178.

11. Nayak, A.R., Chaudhary, D. and Reddy, J.N., 2004. Geneticdivergence in scented rice. Oryza, 41(3\&4): 79-82.

12. Praveen, P., Abhinav, S. and Preeti, S., 
2016. Genetic divergence study in traditional local landraces of rice (Oryza sativa L.) predominant in Bastar Plateau Zone ofChhattisgarh. Advances in Crop Improvement. 7(2): 192-196

13. Ranjith, P. S., Sahu, S.K., Dash, D.N., Bastia and B.D. Pradhan., 2018. Genetic diversity studies in Rice (Oryza sativa L.). Journal of Pharmacognosy and Phytochemistry., 7(2): 2529-2531

14. Rao, B., Murthy, V. A. R. and Subramanya, R. J., 1952. The amylase and amylase pectin content of rice and their influence on cooking quality of cereals, Proc. Indian Acad. Sci., 36:70.

15. Shahidullah, S.M., Hanafi, M.M., Ashrafuzzaman, M., Ismail, M.R. and Salam, M.A., 2009. Phenological characters and genetic divergence in aromatic rice. African Journal of
Biotechnolog., 8(14): 31993207.

16. Singh, R.K. and Chaudhary B.D., 1977. Biometrical methods in quantitative genetics analysis, Kalyani publishers, New Delhi., 318p.

17. Singh, U.K., Mishra, S.B. and Thakur R., 1999. Genetic divergence in boro rice.Oryza., 39(1): 76-77.

18. Sood, S, Sood, K.C. and Kumar S., 2005. Genetic diversity in rice. Research on Crops., 6(2): 290-292.

19. Vivekanandan, P. and Subramanian, S., 1993. Geneticdivergence in rainfed rice. Oryza, 30: 60-62.

20. Vora, Z.N., Patel J.B., Pansuriya A.G. and Yusufzai S. A., 2016. Genetic divergence analysis in bread wheat (Triticumaestivum L.).Res. Environ. Life Sci.10 (3): 291-294.

\section{How to cite this article:}

Parte Deepika, Singh Sanjay and Tiwari Shweta. 2020. Genetic Divergence Analysis in Aromatic and Non- Aromatic Germplasm of Rice. Int.J.Curr.Microbiol.App.Sci. 9(07): 90-99. doi: https://doi.org/10.20546/ijcmas.2020.907.010 